ISSN 1112-9867

Available online at

http://www.jfas.info

\title{
EVALUATING THE EFFECTS OF CLIMATE ON WEATHERING PROCESSES OF ROCKS BASED ON PELTIER MODELS IN KERMANSHAH PROVINCE
}

\author{
H. Farahmand*¹, M. A. Arian ${ }^{2}$, A. Khakzad ${ }^{2}$, M. Afshar ${ }^{3}$ \\ ${ }^{1}$ Department of Geology, North Tehran Branch, Islamic Azad University, Tehran, Iran \\ ${ }^{2}$ Faculty of Basic Sciences, Department of Geology, North Tehran Branch, Islamic Azad \\ University, Tehran, Iran \\ ${ }^{3}$ Industrial Engineering, Qazvin Branch, Islamic Azad University, Qazvin, Iran
}

Published online: 17 June 2016

\begin{abstract}
Weathering is a result of physical, chemical and biological factors, all of which affect the rocks but do not cause Material Handling. The existence of pores and crevices and cracks in the rocks expose the rocks to physical and chemical attack, gradual wracking and being weathered. This study has been based on Louis Peltier's models in which two mean annual temperature and precipitation variables are used. Peltier identified seven models using these two variables which can describe different types of weathering phenomena. Among these models, two models related to weathering regimes and morphogenetic regimes were evaluated in case of Kermanshah province and the regimes related to each station were determined from the related diagrams. Climate data such as mean annual temperature and precipitation and eight synoptic stations which had appropriate data and statistical length were taken from meteorological organization and then were recorded in a database in GIS environment for studying and zoning of the weathering status and geomorphological regions in Kermanshah.
\end{abstract}

Author Correspondence, e-mail: farahmand_hamideh@yahoo.com

doi: http://dx.doi.org/10.4314/jfas.8vi2s.112

Journal of Fundamental and Applied Sciences is licensed under a Creative Commons Attribution-NonCommercial 4.0 International License. Libraries Resource Directory. We are listed under Research Associations category. 
Then, the regimes relating to each station were determined from Peltier models after evaluation of temperature and precipitation processes in the study area which were recorded in the database after giving weighted value to them and then the related maps were generated in ARC map environment. The obtained results showed that most parts of Kermanshah province are semi-arid regions. Chemical weathering along with glacial action to moderate chemical weathering take place in in Kermanshah province in terms of weathering status.

Keywords: Weathering regimes, Peltier model, morphogenetic regions, Kermanshah.

\section{INTRODUCTION}

Weathering occurs when the surface rocks break or change shape as a result of physical, chemical or biological processes which can be caused by wind, water or climate [Rich, 1950].

The Physical weathering is a type of weathering which consists of: geological stresses, all-round tectonic pressures, stresses caused by solar radiation and fast freezing of water. Geological stresses occur when Crystal stones (such as granite and marble) are crystallized or re-crystallized or when sedimentary rocks (like loose and interconnected sandstone pile rocks, arkose and lime) bear the super high pressure of upper layers of lithology phenomena under all-round tectonic pressure. Surface erosion and loss of load will reducing the pressure on it and will create a network of joints and cracks.

Thermal gradient also causes linear and pile expansion of rocks. Also, biological stresses which increase the physical weathering are in two main categories of plants and animals which include worms and mudstones. Chemical weathering is another type of weathering, the mechanism of this weathering represents a complex combination of chemical reactions (Mahmudi, 2003). The solubility of intended minerals depends on the separation amount of $\mathrm{OH}^{-}$and $\mathrm{H}^{+}$ions in water which is shown by the level of $\mathrm{pH}$.

$\mathrm{H}^{+}$ions are small and have high electrical load and are suitable for cracking the minerals' network and taking the cations out. This reaction between cations and $\mathrm{OH}^{-}$ions is called hydrolysis. Also, water can enter the minerals' network through dehydration phenomenon and can pave this phenomenon for weathering by oxidation and carbonation. Elements transfer their electrons to oxygen ions in the solution during the process of oxidation and carbonation occurs as a result of the action of carbonic acid on calcite. 
Weathering rate is set with factors such as the amount of water entered the weathered mass and the amount of water coming out of it, the chemical composition of water and organic matters. Increasing the temperature by 10 degrees doubles the speed of chemical reactions [Gharib, 2003]. In arid regions where water moves upward based on capillary rise and in places with saturated water, montmorillonite, illite and chlorite form the Clay products resulted from the breakdown. Conditions such as good drainage, intense washing and abundance of vegetation cover lead to deep and wide weathering in humid regions.

Biochemical weathering is another type of weathering which exists in all weathered areas and creates a complex series of biochemical processes which includes cation exchange with roots, creating false colloidal solutions and dissolution by root exudates and production of organic acids. This means that the intensity of weathering can be increased up to 10 times compared to pure water due to the effect of weak acids and acetic acid, aspartic acid, tartaric and citric acid increase up the weathering intensity up to 100 times compared to pure water. Humic acids are active in chelation phenomenon and break down silicates, especially amphiboles. Folic acid (which are humic acids derived from leaf soil and peat) are particularly among important factors of weathering. Acids produced by bacteria are also effective in weathering. These acids attack a high number of minerals such as magnesium carbonates and $\mathrm{Mg}$ and $\mathrm{Ca}$ silicates and feldspars and kaolinite but silicates rich in aluminum are not affected by these acids [Gharib, 2003]. Weathering depends on several factors, most common of which are weather conditions and physical and chemical composition of parent rocks [Selby, 1993].

The type of rocks and their feature, wear down of hard rocks connected to domains threatens regional stability in terms of climate territory (Rajaie, 1994). This instability is a great risk for rural and urban housing, tourist facilities and industrial plants which are being built at the foot of the mountain. Determination of the degree of weathering of rocks and mapping and profile analysis of weathered Rocks' subsurface in engineering projects such as building, Road and dams construction and many other engineering structures reveals the need for studying weathering processes (Karami, 2004).

Studies of weathering on the one hand take time due to the slow processes and on the other hand, are more than one process in an active location and most of the times we cannot be sure that the resulting shapes are resulted from which special process. Thus, studies related to weathering 
have been focused on laboratory simulation in the past quarter of a century in order to study the effects of weathering processes separately and under controlled condition and then compared the results with natural conditions. Iran's geographic position on Earth and distribution and deployment of many villages and towns in high-risk earthquake zone or sliding slopes or others have made the human settlements vulnerable to natural phenomena [Afrakhteh, 1997]. Thus, most of the geomorphological studies in Iran have focused on weathering processes of active morphogenesis systems in mountainous areas and morphogenetic risks arising from them and despite the fact that numerous scientific research have been carried out in recent years by paying attention to geological and geomorphological bottlenecks in urban and rural areas for planning and implementation of development projects but the exacerbation of morphogenesis factors and occurrence of hazards such as mass destruction of domain materials after implementation of project show the need for comprehensive and detailed studies in this area.

Therefore, identifying problems and bottlenecks caused by weathering processes whether in form of threatening residential areas (urban and rural) and their effect on engineering projects such as building, Road and dams construction and other structures reveal the need for studies related to weathering and degradation in planning and implementation of development projects of the study area.

Louis Pelletier's model about climate geomorphology is the best source of weathering processes which is used by geologists, geomorphologists and other related sciences to identify and interpret the earth's surface forms [Fowler and Petersen, 2003]. The mean annual temperature and mean annual precipitation are two variables that have a major role in weathering and can be used in identification of weathering regimes. Peltier identified seven models using these two variables which can describe different types of weathering phenomena which include: chemical weathering, glacial activity, weathering regimes, rain erosion, and mass movements of materials, wind activity and morphogenetic regimes. Chemical weathering occurs in places which have high levels of water and temperature. The model is designed in a way that wettest and warmest areas have the maximum chemical weathering and the driest and coldest areas have minimum chemical weathering. Glacial activity (physical weathering) occurs in areas with very low temperatures where mechanical weathering is preferable to chemical weathering. 
Weathering is among external factors affecting the deformation of the earth's crust in which rocky outcrops or dense material of Earth's crust break and turn into discontinuous materials [Khanlari, 1998]. This process changes the existing forms and creates new shapes [Rajaie, 1994]. From the perspective of Memarian (1987) and Selby (1985), weathering is a process which leads to alteration and fragmentation of rocks in its place under the effect of physical, chemical and biological factors. In general, weathering processes are crush rocks into smaller pieces without changes in their minerals in two mechanical destruction processes and chemical decomposition processes. The second group processes are those processes during which rocks and minerals have changes in their chemical composition in addition to physical changes and cause fragmentation and disintegration of Earth's crust Rocks [Khanlari, 1998].

These two processes usually weather the rocks together and with the help of each other. However, Khanlari (1377) and Saviz (1989) have considered biological weathering as another type of weathering which occurs due to organisms on Earth such as changes caused by the roots of plants or other organisms such as bacteria.

This study ties to classify the weathered zones (low, medium, high) of Kermanshah Province based on climatic variables in addition to evaluation of factors affecting weathering and mechanism of their processes.

\section{The study area}

Kermanshah province with an area of 24641 square kilometers is located in West of Iran between ' $41^{\circ} 33$ to ' $17^{\circ} 35$ North latitudes and ' $06^{\circ} 48$ to ' $24^{\circ} 45$ East longitudes. Its capital is the city of Kermanshah and its height from sea level is $1322 \mathrm{~m}$. The province is limited to Kurdistan province from north, to Lorestan and Ilam provinces from south, to Hamedan province from East and to Iraq from West. The location of Kermanshah province in Iran as well as geographic location of used stations has been shown in figure 1 and statistical characteristics of 8 used stations have been shown in table 1 . 


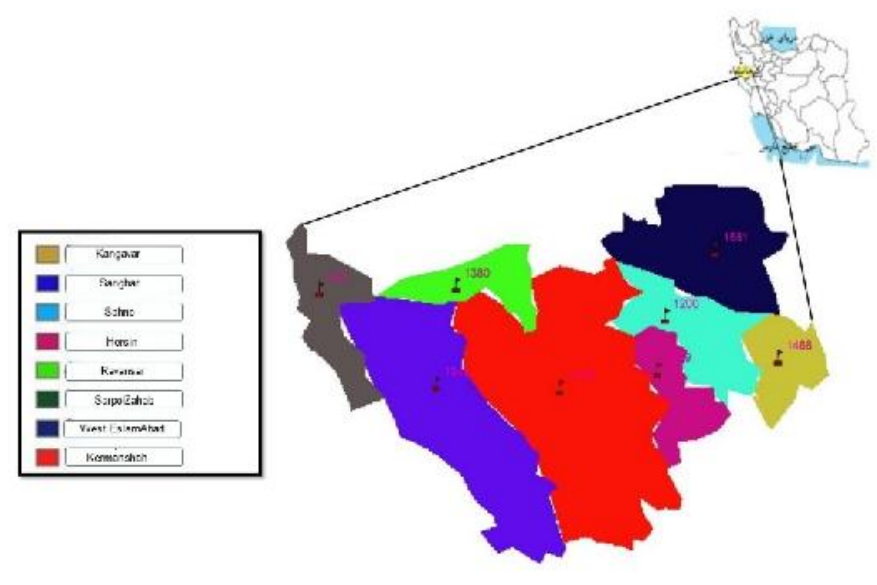

Fig.1.geographical location of stations used in Kermanshah

Table 1. Characteristics of used weather stations in Kermanshah Province

\begin{tabular}{|c|c|c|c|c|c|}
\hline raw & $\begin{array}{l}\text { Name of the } \\
\text { station }\end{array}$ & Longitude & latitude & Height (m) & $\begin{array}{l}\text { Type of the } \\
\text { station }\end{array}$ \\
\hline 1 & Kermanshah & $47^{\circ} 9^{\prime}$ & $34^{\circ} 21^{\prime}$ & $1318 / 6$ & Synoptic \\
\hline 2 & $\begin{array}{c}\text { West } \\
\text { EslamAbad }\end{array}$ & $46^{\circ} 39^{\prime}$ & $34^{\circ} 43^{\prime}$ & 1349 & Synoptic \\
\hline 3 & Kanngavar & $45^{\circ} 52^{\prime}$ & $34^{\circ} 27^{\prime}$ & 1468 & Synoptic \\
\hline 4 & Ravansar & $46^{\circ} 39^{\prime}$ & $34^{\circ} 43^{\prime}$ & 1380 & Synoptic \\
\hline 5 & Sarpolzahab & $45^{\circ} 52^{\prime}$ & $34^{\circ} 27^{\prime}$ & 545 & Synoptic \\
\hline 6 & Senghez & $47^{\circ} 57^{\prime}$ & $35^{\circ} 04^{\prime}$ & 1681 & Synoptic \\
\hline 7 & Sahne & $47^{\circ} 68^{\prime}$ & $34^{\circ} 48^{\prime}$ & 1200 & Synoptic \\
\hline 8 & Hersin & $47^{\circ} 35^{\prime}$ & $34^{\circ} 16^{\prime}$ & 1549 & Synoptic \\
\hline
\end{tabular}




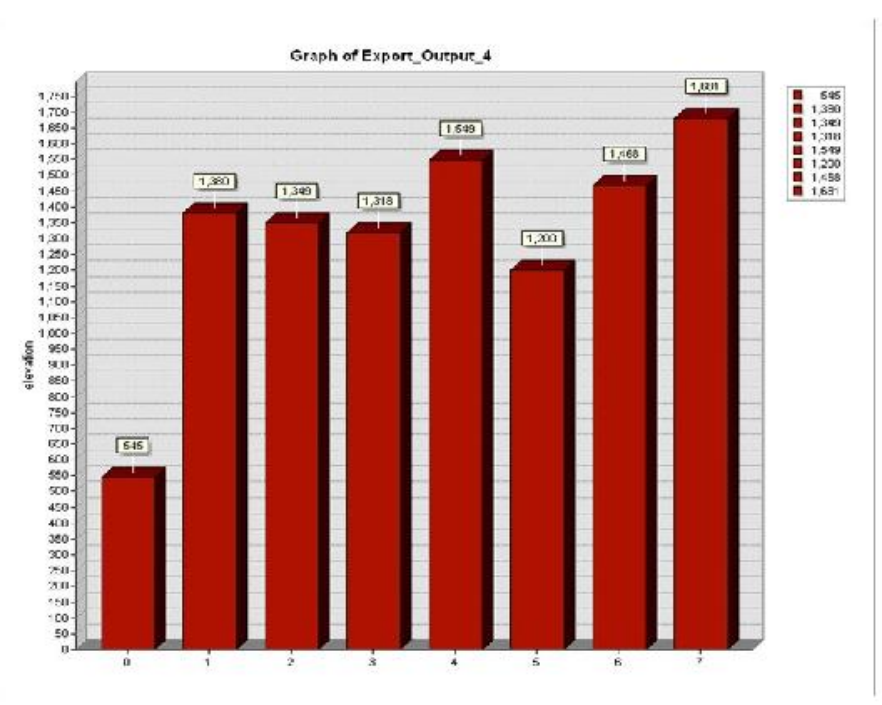

Fig.3. Heights of studied stations of Kermanshah Province have been shown in the diagram

\section{RESEARCH METHODOLOGY}

In this research, climatic parameters of the mean annual temperature and precipitation of the region's synoptic stations have been obtained from meteorological organization to evaluate weathering and its related morphogenetic forms in Kermanshah province and about eight stations which had appropriate data in terms of statistical period's length were selected after elimination of statistical deficiency among all synoptic stations (Table 1). Then, a database was created in Arc GIS and data related to that environment were recorded and then, the analysis was done in ArcMAP environment and different maps were drawn. Then, the Peltier models were used to determine the weathering status in Kermanshah province, among which two cases which can properly describe weathering status and related forms were used which are:

\section{A) Weathering regimes}

Figure 4 has shown the division of weathering regimes in Peltier graph. Two mean annual temperature and precipitation variables have been used in this model and weathering regimes have been categorized into seven different categories and each area represents a type of weathering condition. This model is designed in a way that wettest and warmest areas have the maximum chemical weathering and the driest and coldest areas have minimum chemical weathering. Glacial activity (physical weathering) occurs in areas with very low temperatures where mechanical weathering is preferable to chemical weathering. 


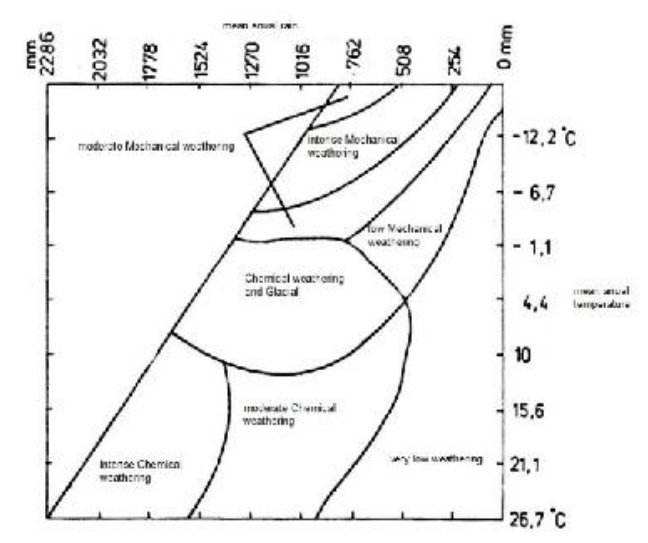

Fig.4. Division of weathering regimes in the Peltier graph (1950)

\section{B) Morphogenetic zones}

Morphogenetic regimes' model which is more similar to climate and herbal classifications than weathering model has been shown in figure 5. Average temperature and annual rainfall variables were also used in these model and morphogenetic zones were divided into 9 different classes. Areas with low temperatures are mainly glacial areas and areas with high temperatures and low rainfall are arid and semi-arid areas and areas with high rainfall and temperatures are considered among mild and Selva areas. Table 2 shows the morphogenetic areas based on Peltier division along with their morphological features. 
Table 2. Morphogenetic areas based on Peltier division (1950)

\begin{tabular}{|c|c|c|c|}
\hline Morphological area & $\begin{array}{l}\text { mean annual } \\
\text { temperature }\end{array}$ & mean annual rainfall & $\begin{array}{c}\text { Morphogenetic } \\
\text { features }\end{array}$ \\
\hline Glacial & -18 to -7 & 0 to 1400 & $\begin{array}{l}\text { Glacial erosion, } \\
\text { nivation }\end{array}$ \\
\hline Near Glacial & -15 to -1 & 130 to 1400 & $\begin{array}{l}\text { The effect of wind, } \\
\text { heavy mass } \\
\text { movements, weak } \\
\text { flowing water activity }\end{array}$ \\
\hline boreal & -9 to +3 & 250 to 1520 & $\begin{array}{l}\text { Effects of Moderate } \\
\text { frost, wind and water } \\
\text { effects moderate to } \\
\text { poor }\end{array}$ \\
\hline Oceanic & +2 to +21 & 1270 to 1900 & $\begin{array}{c}\text { intense Mass } \\
\text { movements, moderate } \\
\text { to poor flowing water } \\
\text { activity }\end{array}$ \\
\hline Selva & +16 to +29 & 1400 to 2290 & $\begin{array}{c}\text { intense mass } \\
\text { movements, washing } \\
\text { domains in low level }\end{array}$ \\
\hline mild & +3 to +29 & 890 to 1520 & $\begin{array}{l}\text { The maximum flowing } \\
\text { water activities, low } \\
\text { effect of freezing and } \\
\text { semi-arid wind }\end{array}$ \\
\hline Savan & -12 to +29 & 640 to 1270 & $\begin{array}{l}\text { intense to low flowing } \\
\text { water activities, } \\
\text { moderate wind effect }\end{array}$ \\
\hline Semiarid & +2 to +29 & 250 to 640 & $\begin{array}{l}\text { The effects of high } \\
\text { wind, flowing water } \\
\text { activity of moderate to } \\
\text { severe }\end{array}$ \\
\hline Arid & +13 to +29 & 0 to 380 & $\begin{array}{l}\text { The effects of high } \\
\text { wind, flowing water } \\
\text { activity and weak mass } \\
\text { movements }\end{array}$ \\
\hline
\end{tabular}




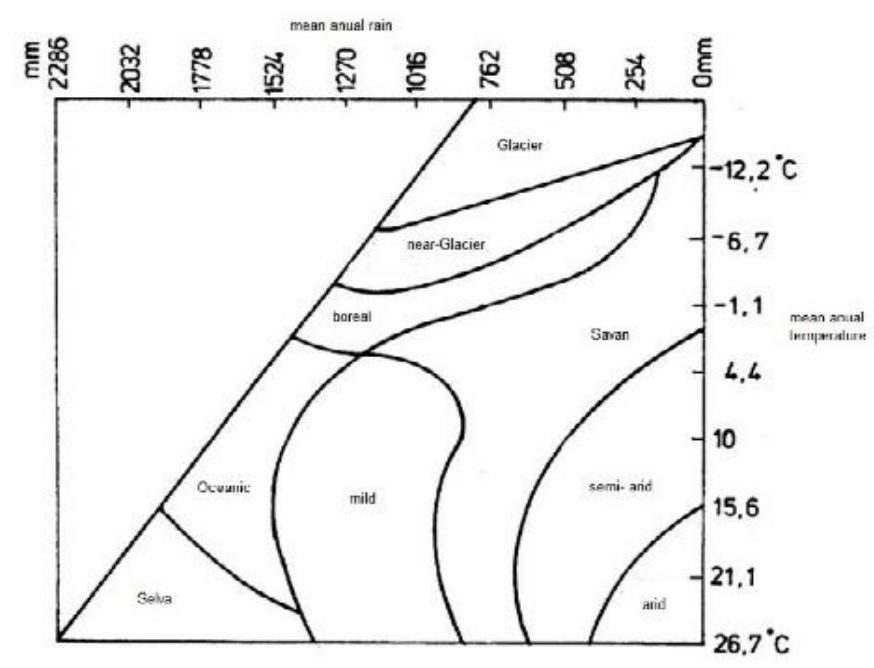

Fig.5. Morphogenetic areas based on Peltier division

\section{Findings}

Rocks show different resistance to weathering due to their constructive minerals, texture and structure (Memarian, 2000). On the other hand, temperature change due to crioclastia and termoclastia phenomena and moisture due to hidroclasia and haroclasia have significant impacts (Rajaie, 1994).

Kermanshah province was evaluated in terms of the status of morphogenetic areas after obtaining the general attitude of temperature and precipitation processes and a weight value was given to each station as Code and were entered into the database after obtaining the location of each station in Peltier model. Then, inverse weighting interpolation (IDW) was used for zoning of these areas in GIS environment using existing spatial interpolation methods and spatial analysis of geospatial data, this model is in a way that the effect of one parameter to the surrounding points in an interpolation level is not same and close points are affected more and far points will be affected less depending on their distance from the source. The raster layers were re-classified in the next phase and a coefficient of 1 to 5 was given to each situation and the map of the morphogenetic status of the area was generated. The results showed that from 9 morphogenetic statuses in the Peltier model, 2 status occur in climatic conditions. Most parts of the study area are located in semi-arid areas which their most important morphogenetic feature are the effects of moderate to severe wind and flowing water activities (figure 6). 
Finally Kermanshah province was evaluated in terms of weathering regimes' status and the status relate to each station was entered into the database in form of code value after obtaining the location of each station in Peltier model and the raster layer was re-classified for zoning of these areas in GIS environment and a coefficient of 1 to 5 was given to each status in a way that the lowest coefficient was given to weak weathering and the highest coefficient was given to intense chemical weathering (table 3). Finally, the zoning map of weathering regimes of the area were generated. The majority of weathering in Kermanshah province is moderate-to-severe chemical weathering due to heavy rainfall and chemical weathering along with glacial action occur in some other stations due to abundant rainfall and low temperatures (figure 7).

Table 3. Type and severity of weathering and their weight values

The type and intensity of weathering

\begin{tabular}{|c|c|}
\hline The type and intensity of weathering & Weight values \\
\hline Very low Weathering & 1 \\
\hline weak Mechanical weathering & 2 \\
\hline Weak chemical weathering with Glacial action & 3 \\
\hline Moderate Chemical weathering & 4 \\
\hline Intense Chemical weathering & 5 \\
\hline
\end{tabular}

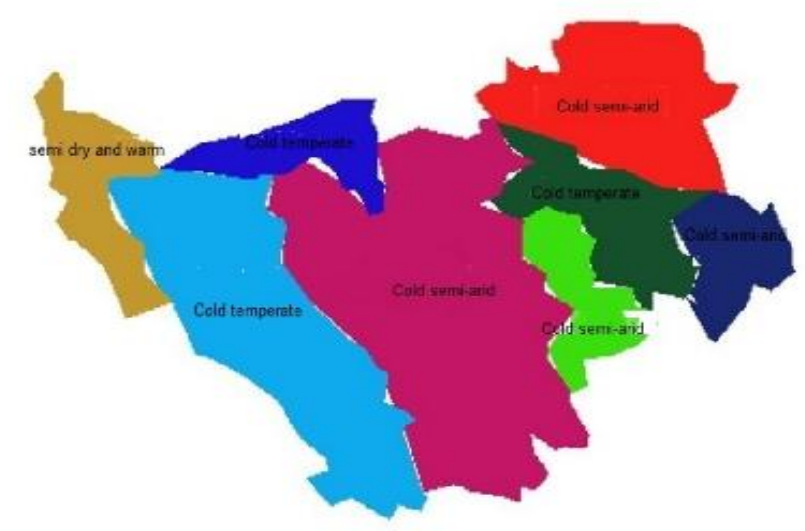

Fig.6. Morphogenetic areas in Kermanshah based on the Division Peltier 

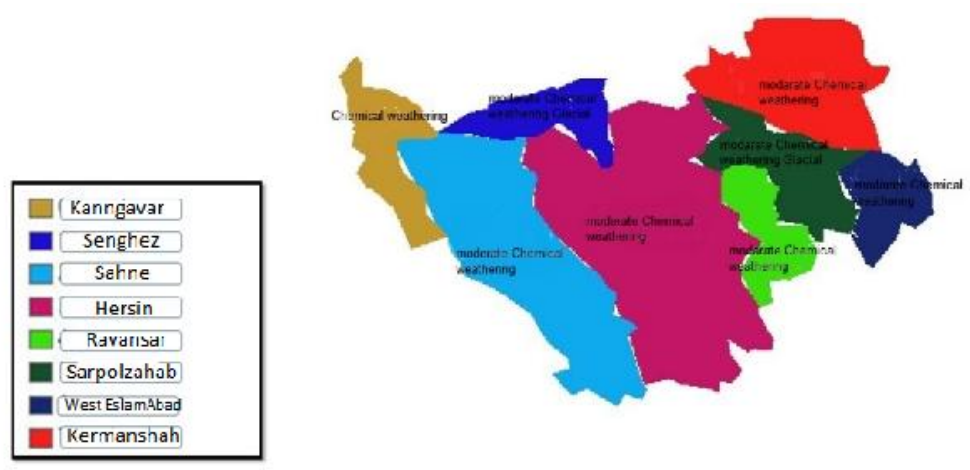

Fig.7. Classification of type and severity of weathering based on Peltier model in Kermanshah (statistical period2005-2014)
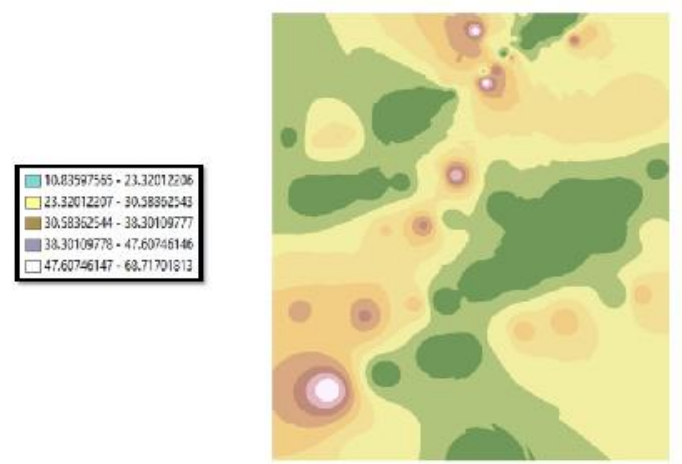

Fig.8. Zoning of mean annual precipitation of synoptic stations of Kermanshah (statistical period2005-2014)
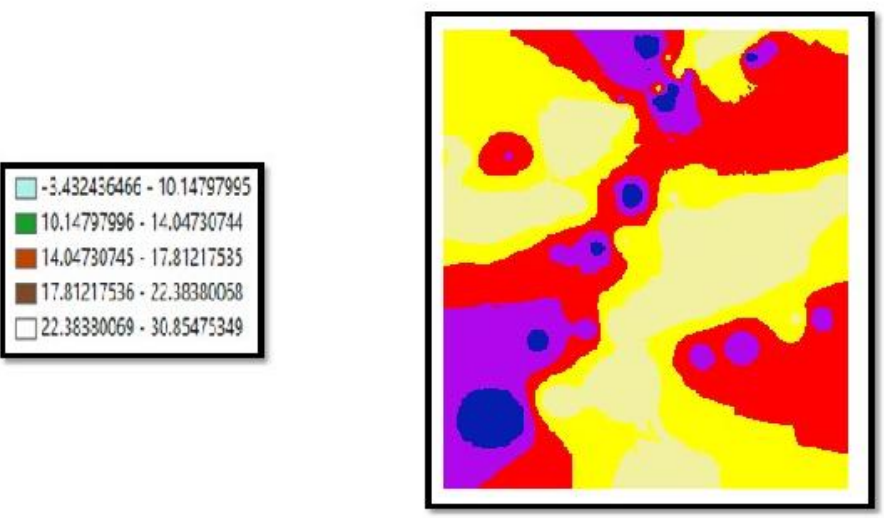

Fig.9. Zoning of mean annual temperature of synoptic stations of Kermanshah (statistical period2005-2014) 


\section{DISCUSSION AND CONCLUSION}

Connected and non-detachable rocks become large and small separate materials due to the effect of weathering processes. These materials rarely remain constant on the slope and start to move due to the effect of gravity force and mass weight of materials or under the effect of transport mechanisms on the slopes and are transferred to the foot of the mountain in different forms. Majority of weathering in Kermanshah province is moderate-to-severe chemical weathering due to heavy rainfall and chemical weathering along with glacial action occur in some other stations due to abundant rainfall and low temperatures. Louis Pelletier's model about climate geomorphology is the best source of weathering processes which is used by geologists, geomorphologists and other related sciences to identify and interpret the earth's surface forms. The mean annual temperature and mean annual precipitation are two variables that have a major role in weathering which have been used in this research. The results of this study were largely satisfactory and created maps can show the status of Kermanshah province in terms of weathering and forms related to it. Several parameters can be effective in weathering processes, among which the mean annual temperature and precipitation are the most important ones and Peltier models are also created based on these two parameters. The results obtained from this research showed that temperature and precipitation regimes depend mostly on latitude and direction and altitude elongation which leads to creation of variations in different parts of the region and generally elevations and their direction have an important role in creation of weathering regimes and the related forms. The results of this study showed that the majority of study areas are located in semi-arid area which it's most important Geo-Morphodynamic feature is the effects of moderate to severe wind and flowing water activities.

\section{REFERENCES}

[1] Current And information obtained from the Meteorological Organization.

[2] Rajaie, Abdul Majid (1994), applied geomorphology in the area of planning and construction, publishing Ghomes.

[3] Gharib, Abdul Karim, (2003), with a special stone to stone Iranian understanding, cultural Nshrlmy. 
[4] Karimi, Fariba. (2004), weathering processes and their impact on urban and rural areas of Azerbaijan, Journal of Geography and Development.

[5] Karimi, Fariba. (2002), examining issues of geomorphology on the northern slopes and plains cumulative Bozghoush Mirage, natural geographic doctor thesis, Faculty of Humanities and Social Sciences, University of Tabriz.

[6] Mahmoudi, Farajallah. (2003), geomorphological dynamics, Fifth Edition, PNU.

[7] Memariann, Hossein. (1990), Geology for Engineers, Fourth Edition, Tehran University Press

[8] Afrakhteh, H., Economic and Social Necessity in Reconstruction of Residential Damaged, Geography Research Quarterly, 1997, No. 4, 120-134.

[9] Dalaloghli, A., 2002, An Investigation to Morphogenesis Systems in North Slope of Sablan and Formation of Meshgin Shahr Accumulation Plain, Ph.D. Thesis, Faculty of human and Social Science, Tabriz University.

[10] Fowler, Rell, Petersen, James, 2003, A Spatial Representation of Louis Peltier's Weathering, Erosion and Climatic Graphs Using Geographic Information Systems (GIS), GEO 5419, Advanced GIS II. Spring.

[11] Gharib, A., 2003, Stone Recognition with a Especial Glimpse to Iran Stones, Tehran, Elmi va Farhangi Publication.

[12] Mireille, Bouchard, Serge, Jolicoeur, Chemical Weathering Studies in Relation to Geomorphological Research in Southeastern Canada, Geomorphology, 2000, 32, 213-238.

[13] Peltier, Louis C., The Geographic Cycle in Periglacial Regions as it is Related to Climatic Geomorphology, Annals of the Ass ociation of American Geographers, 1950, 40, 214-236.

\section{How to cite this article:}

Farahmand H, Arian MA, Khakzad A, Afshar M. Evaluating the effects of climate on weathering processes of rocks based on peltier models in kermanshah province. J. Fundam. Appl. Sci., 2016, $8(2 S), 784-797$. 